\title{
Synaptic Plasticity in Fear Conditioning Circuits: Induction of LTP in the Lateral Nucleus of the Amygdala by Stimulation of the Medial Geniculate Body
}

\author{
Marie-Christine Clugnet and Joseph E. LeDoux \\ Center for Neural Science, New York University, New York, New York 10003
}

\begin{abstract}
Electrical stimulation of the medial geniculate body in the anesthetized rat produces an evoked potential in the lateral nucleus of the amygdala. The potential varies in amplitude with stimulus intensity and reaches peak amplitude in 8.5 msec on the average. High-frequency stimulation of the pathway produces long-lasting increases in the amplitude and slope of the potential. These robust and enduring experience-dependent modifications in neural transmission occur in a pathway known to be involved in the formation of emotional memories and may offer a means for examining the cellular mechanisms of emotional learning, as well as a new approach to questions concerning the relevance of longterm potentiation to normal mnemonic processes.
\end{abstract}

Projections from the medial geniculate body (MGB) to the amygdala mediate the formation of emotional memories established by pairing an acoustic stimulus with footshock (LeDoux et al., 1984, 1985, 1986, 1990b; Iwata et al., 1986). The critical projection terminates in the lateral nucleus of the amygdala $(\mathrm{AL})$ (LeDoux et al., 1990a), which contains a high concentration of excitatory amino acid receptors (Monaghan and Cotman, 1985). In the hippocampus, excitatory amino acid receptors play an important role in long-term potentiation (LTP) (Dunwiddie et al., 1978; Collingridge et al., 1983; Nowak et al., 1984; Lynch and Baudry, 1984; Collingridge, 1985; Morris et al., 1986; Cotman et al., 1988), an enhancement of synaptic efficacy produced by high-frequency stimulation of afferent pathways (Bliss and Lomo, 1973; Eccles, 1987; Teyler and DiScenna, 1987; Brown et al., 1988). Recent studies demonstrate that LTP can be induced in AL by applying high-frequency stimuli to the external capsule (Chapman and Brown, 1988). If LTP could also be produced in AL by stimulating the cells of origin of the geniculoamygdala pathway, a model would be available for examining synaptic plasticity in an emotional learning circuit and thus possibly the cellular mechanisms underlying the formation of emotional memories. While evidence to date linking LTP to normal learning and memory processes is suggestive but weak

\footnotetext{
Received Apr. 4, 1990; accepted Apr. 10, 1990.

Supported by MH 38774 and a Grant-in-Aid from the New York Heart Association. J.E.L. is an Established Investigator of the American Heart Association. We thank Dr. Constantine Pavlides for his advice in the beginning phases of this study. The work described was performed, in part, in the Laboratory of Neurobiology, Department of Neurology, Cornell University Medical College, New York, NY. The term "LTP cascade" was suggested by one of the anonymous reviewers of this paper.

Correspondence should be addressed to Dr. J.E. LeDoux, Center for Neural Science, New York University, 6 Washington Place, New York, NY 10003.
}

Copyright (C) 1990 Society for Neuroscience $0270-6474 / 90 / 082818-07 \$ 03.00 / 0$
(Swanson et al., 1982; Teyler and DiScenna, 1987; Brown et al., 1988), the demonstration of LTP in the geniculoamygdala projection system would provide a new and perhaps more viable approach for examining the functional significance of LTP than has been possible through studies of the hippocampus. We therefore examined whether we could produce LTP in AL by stimulating the cells of origin of the geniculoamygdala projection.

\section{Materials and Methods}

Male Sprague-Dawley rats $(n=30)$ weighing 250-300 gm were anesthetized with chloral hydrate $\left(7 \%\right.$ in $\mathrm{H}_{2} \mathrm{O} ; 420 \mathrm{mg} / \mathrm{kg}$, i.p.), paralyzed with $d$-tubocurarine $(0.6 \mathrm{mg} / \mathrm{kg}$, i.v), and artificially respirated (Harvard Apparatus Rodent Ventilator; $2.5 \mathrm{cc} / \mathrm{stroke}, 40$ strokes/min). In some studies, supplemental doses of the 2 drugs were given alternately every $30 \mathrm{~min}$, whereas in other studies, the drugs were mixed and continuously infused intravenously $(0.2 \mathrm{ml} / \mathrm{min})$. The latter proved to be the better technique for maintaining a constant level of anesthesia. Body temperature was maintained at $37^{\circ} \mathrm{C}$ throughout the experiment.

Anesthetized rats were placed in a stereotaxic frame and the cranium above the MGB and amygdala was exposed and the dura retracted. A bipolar concentric stimulating electrode $(R=10 \mathrm{k} \Omega)$ was lowered to the $\mathrm{MGB}$ at a $20^{\circ}$ angle to the coronal plane and a steel microelectrode ( $\mathrm{R}$ $=2-5 \mathrm{M} \Omega$ ) was positioned in AL (Clugnet and LeDoux, 1989). Unit activity was amplified, and discriminated output was viewed on an oscilloscope. Search stimuli (biphasic pulses, $250 \mu \mathrm{sec}$ half-width, 500 $\mu \mathrm{A}, 0.1 \mathrm{~Hz}$ ) were used to confirm the location of the recording electrode in an area receiving afferents from the MGB. If short-latency unit responses $(3-10 \mathrm{msec})$ were not elicited, the recording electrode was repositioned.

Once the recording electrode was correctly placed, the electrical recording was low pass-filtered $(300 \mathrm{~Hz}$ cutoff) to record an evoked potential. The amplitude of the potential was reduced to one-third of its average peak-to-peak amplitude by decreasing the intensity of the stimulus. This intensity was then used as the "test stimulus" throughout the experiment.

Through pilot studies (see Results), effective tetanization parameters were determined: 10-train stimuli consisting of 30 biphasic pulses ( 2 msec apart, $250 \mu \mathrm{sec}$ half-width, twice the intensity of the test stimulus) at $400 \mathrm{~Hz}$ once each second. This was repeated 5 times, once every 5 min. Immediately following each tetanization trial, one test, consisting of 20 repetitions of the test stimulus at a rate of $0.3 \mathrm{~Hz}$, was performed. Following the final tetanization, 2-6 tests, each consisting of 20 repetitions of the test stimulus, were performed at $10 \mathrm{~min}$ intervals. No other stimuli were given during this time.

The wave forms elicited by test stimuli were digitized (at 1000--2000 $\mathrm{Hz}$ ) and analyzed using the Cambridge Electronic Design 1401 and its Multichannel Signal Average software. For each test period, the evoked responses to the 20 test stimuli were averaged. The amplitude of the averaged potential was measured peak-to-peak (between the onset of the response and the positive peak and between the positive peak and the offset). The mean of these 2 measures was obtained (ignoring the sign of the values) and used as the measure of average amplitude. The percent change in average amplitude after tetanization was calculated as

$$
\left[\left(V_{t}-V_{b}\right) / V_{b}\right] \cdot 100,
$$

where $V_{t}$ is the average amplitude of the potential at time $t$ and $V_{b}$ is 
the mean amplitude of the baseline period (measured in 1-3 pretetanization control tests). LTP was defined as a change in amplitude of at least $10 \%$ at $20 \mathrm{~min}$ after the final tetanization.

The locations of the recording and stimulating electrodes were marked by introducing small lesions (100-150 $\mu \mathrm{A} \mathrm{DC}, 7 \mathrm{sec}$ ). Animals were perfused with $10 \%$ buffered formalin containing potassium ferricyanide $(5 \%)$ and potassium ferrocyanide $(5 \%)$. Brains were removed, postfixed overnight, frozen, and sectioned $(50 \mu \mathrm{m})$ on a sledge microtome. The sections were mounted on gelatin-coated slides, stained in thionin $(0.25 \%)$, dehydrated, and coverslipped. The lesion locations were identifiable as blue spots under microscopic examination.

\section{Results}

Characterization of the evoked potential

In extracellular recording studies, changes in the amplitude and slope of evoked potentials are often used as measures of LTP. Our first objective was therefore to determine whether we could reliably evoke potential changes in AL by stimulating the MGB.

Electrical stimulation of the MGB elicits increases in unit discharge rates in AL (Clugnet et al., 1990). Typically a cluster of units respond with an onset latency of about 4-8 msec and a duration of about 5-8 msec (Fig. 1a). When unit activity is low-pass-filtered ( $300 \mathrm{~Hz}$ cutoff), the evoked activity can be seen as a positive potential lasting about $5 \mathrm{msec}$ (Fig. $1 \mathrm{~b}$ ). The onset of the potential occured at $8.5 \mathrm{msec}$ on the average but varied from animal to animal between 4.5 and $13 \mathrm{msec}$. The origin of this variability is not understood at present, but the variability may be a significant predictor of whether LTP occurs (see below). The onset of the potential is, in some instances, slightly delayed (1-2 $\mathrm{msec})$ with respect to the onset of unit activity. The amplitude of the potential varies as function of the intensity of the stimulus.

\section{Preliminary tetanization studies}

Since LTP has not been previously induced in the amygdala by stimulating the acoustic thalamus, it was necessary to conduct a series of pilot studies to determine appropriate stimulus parameters. Initially, we adopted parameters that have proven useful with in vivo studies of LTP in the hippocampus. In the first 2 rats, 10 monophasic train stimuli consisting of 10 pulses (250 $\mu \mathrm{sec}$ each) at $400 \mathrm{~Hz}$ were delivered every $3-5 \mathrm{sec}$. Since the amplitude of the potential did not change, a long train (100200 pulses) was delivered at the end of the experiment. In both rats, the amplitude of the potential clearly increased. Over the next several experiments, the frequency of the train stimulus $(50,100,200$, or $400 \mathrm{~Hz})$ and the number of pulses in each train (10-50 pulses in increments of 10$)$, and the delay between adjacent trains $(1-5 \mathrm{sec})$ were systematically varied. The conclusion from the studies was that an effective stimulus for inducing changes in the amplitude of the potential is 10 trains consisting of 30 pulses at $400 \mathrm{~Hz}$, delivered once each second. Subsequently, monophasic pulses were replaced with biphasic stimuli (250 $\mu \mathrm{sec}$ half-width, $2 \mathrm{msec}$ apart). These parameters were effective, but the increase in the amplitude of the potential was, in some instances, maintained for only 5-10 min after a single tetanization. We then determined that $4-5$ repetitions of the tetanizing stimulus, once every $5 \mathrm{~min}$, more consistently resulted in a prolonged maintenance of the amplitude change. This last set of parameters, depicted in Figure 2, was routincly used in subsequent studies.

\section{Induction of LTP}

Using the parameters depicted in Figure 2, an additional 24 experiments were performed. LTP (an increase of at least $10 \%$
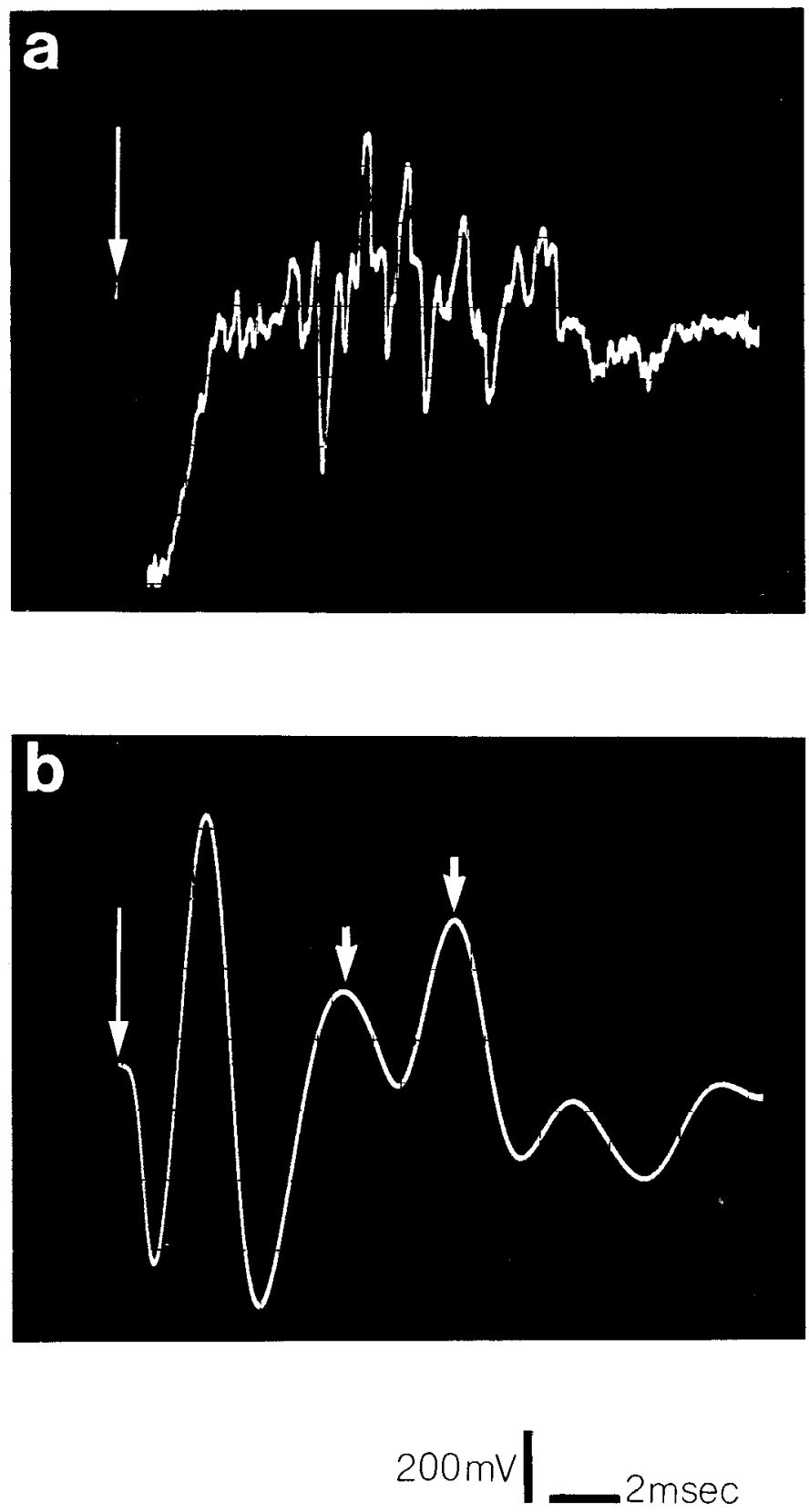

Figure 1. Comparison of the unit responses $(a)$ and evoked potential (b) in the lateral nucleus of the amygdala produced by electrical stimulation (biphasic pulses, $250 \mu \mathrm{sec}$ half-width, $500 \mu \mathrm{A}, 0.1 \mathrm{~Hz}$ ) of the medial geniculate body. The recordings shown in $a$ and $b$ are from the same electrode placements, the only difference being that $b$ was lowpass-filtered (bandpass, $0-300 \mathrm{~Hz}$ ). Stimulus onset is indicated by the long arrows. Onset and offset of the positive (downward) evoked potential in $b$ are indicated by short arrows. The large deflection between the onset of the stimulus and the onset of the evoked response in $b$ is the stimulus artifact.

in the peak-to-peak amplitude of the evoked potential $20 \mathrm{~min}$ after the final tetanization) was induced in 10 animals. Because of technical problems during the recording, 2 of the 10 cases in which LTP was induced are not included in the data analysis.

A representative recording of the averaged evoked response produced by 20 repetitions of the test stimulus before and at several time points after tetanization is shown in Figure 3. The amplitude of the evoked response is clearly greater after than 


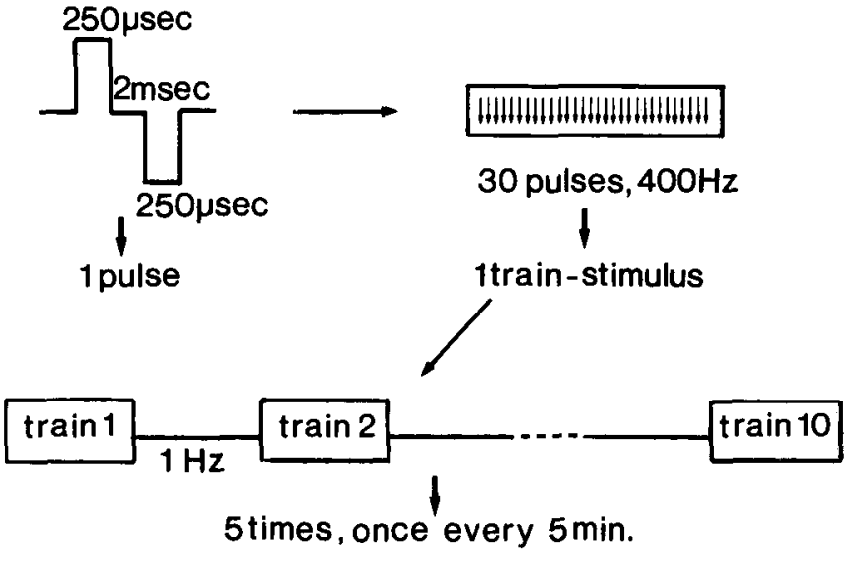

Figure 2. Stimulation conditions used to tetanize thalamoamygdala projections. Effective tetanizing parameters were determined through pilot studies: 10 trains of 30 pulses of a biphasic stimulus $(250 \mu \mathrm{sec}$ half-width, 2 msec apart) at $400 \mathrm{~Hz}$, delivered once each second. Immediately following each tetanization trial, one test, consisting of 20 repetitions of the test stimulus at a rate of $0.3 \mathrm{~Hz}$, was performed (not shown). Following the final tetanization, 2-6 tests were performed at 10 min intervals.

before tetanization and the increase is maintained for more than $50 \mathrm{~min}$ (the longest time examined).

For the group of 8 animals included in the data analysis, the amplitudc of the potential was significantly greater 20 min after the final (fifth) tetanization trial than before tetanization $(t=$ $3.81,7 d f, p<0.01$; Fig. 4). The amplitude increased by $40 \%$ (range, 10-60\%).

An increase in amplitude was usually apparent after a single tetanization trial. In some instances, this increase decayed, thus prompting us in pilot studies (see above) to use multiple tetanization trials. Amplitude was typically greatest immediately after tetanization, reflecting posttetanic potentiation. Thus, the average amplitude over 20 test stimuli, though greater than baseline, was typically less than the amplitude obtained in the first test trial conducted immediately after tetanization.

The amplitude of the facilitated potential was maintained above pretetanization values for at least $20 \mathrm{~min}$ after the fifth tetanization in all cases, and in 4 of the 8 animals it remained elevated after $50 \mathrm{~min}$ (the longest time examined). The amplitude at $20 \mathrm{~min}$ was intcrpolated in 2 animals for which measurcs were available only at times preceding and following $20 \mathrm{~min}$. In the 4 instances where amplitude returned to baseline within $60 \mathrm{~min}$, the decrement usually followed the administration of anesthestic supplements. In experiments where anesthesia was continuously infused, the amplitude was more consistently maintained.

The latency of the peak amplitude of the potentials before tetanization ranged between 6 and $14 \mathrm{msec}$ across all animals studied and was shorter in animals that exhibited LTP (8.9 \pm $2.6 \mathrm{msec})$ than in animals that did not $(12.4 \pm 1.7 ; t=3.16,8$ df, $p<0.01$ ). This occured despite the fact that the onset latencies of unit responses did not differ in animals that did (5.0 $\pm 1.4)$ and did not $(5.0 \pm 1.5)$ exhibit LTP. The latency of the peak of the potential was not affected by tetanization in most experiments, but in one case the peak latency was 2 msec shorter after tetanization.

Changes in the slope of the potential were also measured. The initial (rising) slope of the potential was significantly greater after than before tetanization $(t=4.36,7 \mathrm{df}, p<0.01$; Fig. 4). Slope increased by $71 \%$ after the final tetanization relative to the pretetanization value. In retrospect, slope seems to be a more sensitive measure of LTP in this preparation.

In 9 of the 10 animals in which LTP was induced, the recording electrode was successfully placed in AL (Fig. 5). In the other animal, the recording electrode was in the adjacent amygdalostriatal transition area, which also receives afferents from the MGB. Of the 14 cases where LTP was not induced, the stimulating electrode was outside of the MGB in 1 case and the recording electrode was located outside of the MGB projection field in the amygdala in 3 other cases. In the latter 3 cases, the recording electrode was located in the endopiriform nucleus, the external capsule, or the central nucleus of the amygdala (Fig. 5). Experiments with placements located within AL and the amygdalostriatal transition area that did not show LTP could not be distinguished from those that did show LTP using anatomical criteria.

For placements in the endopiriform nucleus and external capsule, evoked potentials, but not unit responses, were recorded prior to tetanization. For all other placements, both unit responses and evoked potentials were recorded. The combined presence of unit responses and an evoked potential thus does not directly predict whether LTP will be induced.

\section{Discussion}

In the present study we have demonstrated that delivery of repetitive, high-frequency electrical stimuli to the acoustic thalamus induces an increase in the amplitude and slope of an evoked potential recorded extracellularly in AL. The changes are relatively robust, involving a mean increase in amplitude of $40 \%$ and a mean increase in slope of $71 \%$. The changes are also enduring, as they can be maintained for more than $50 \mathrm{~min}$ in many preparations. Such modifications in electrical activity by high-frequency stimulation of afferent pathways are usually referred to as instances of LTP and are believed to reflect changes in the efficacy of synaptic transmission (Bliss and Lomo, 1973; Teyler and DiScenna, 1987; Brown et al., 1988).

Potentials recorded in areas that are outside of the geniculoamygdala projection field (i.e., endopiriform cortex, external capsule, central nucleus of the amgydala) were not modified by tetanization of the acoustic thalamus. However, LTP was not always seen within areas of the geniculoamygdala projection ficld (i.c., AL, amygdalostriatal transition arca).

LTP was more likely to be present when the evoked potential had a relatively short latency than when it had a longer latency. It is unclear at present why the latency of the evoked potential varies from animal to animal and why long-latency evoked potentials are less likely to undergo facilitation, given the fact the unit responses elicited by the stimulus were essentially the same in animals that did and did not exhibit LTP.

The mechanisms underlying the induction of LTP in AL by stimulation of the acoustic thalamus are unknown. However, it seems probable that, as in hippocampus (Collingridge et al., 1983; Harris et al., 1984; Lynch and Baudry, 1984; Wigstrøm and Gustafsson, 1985; Morris et al., 1986), excitatory amino acid transmission will be implicated. Glutamate is present in the thalamic cells of origin and in presynaptic terminals in $\mathrm{AL}$ (Farb et al., 1989), and injection of kynurenic acid, a broadspcctrum antagonist of excitatory amino acid transmission, prevents acoustic thalamic stimulation from eliciting unit discharges in AL (Clugnet and LeDoux, 1989). Moreover, excitatory amino acid receptors, including NMDA receptors, are highly 

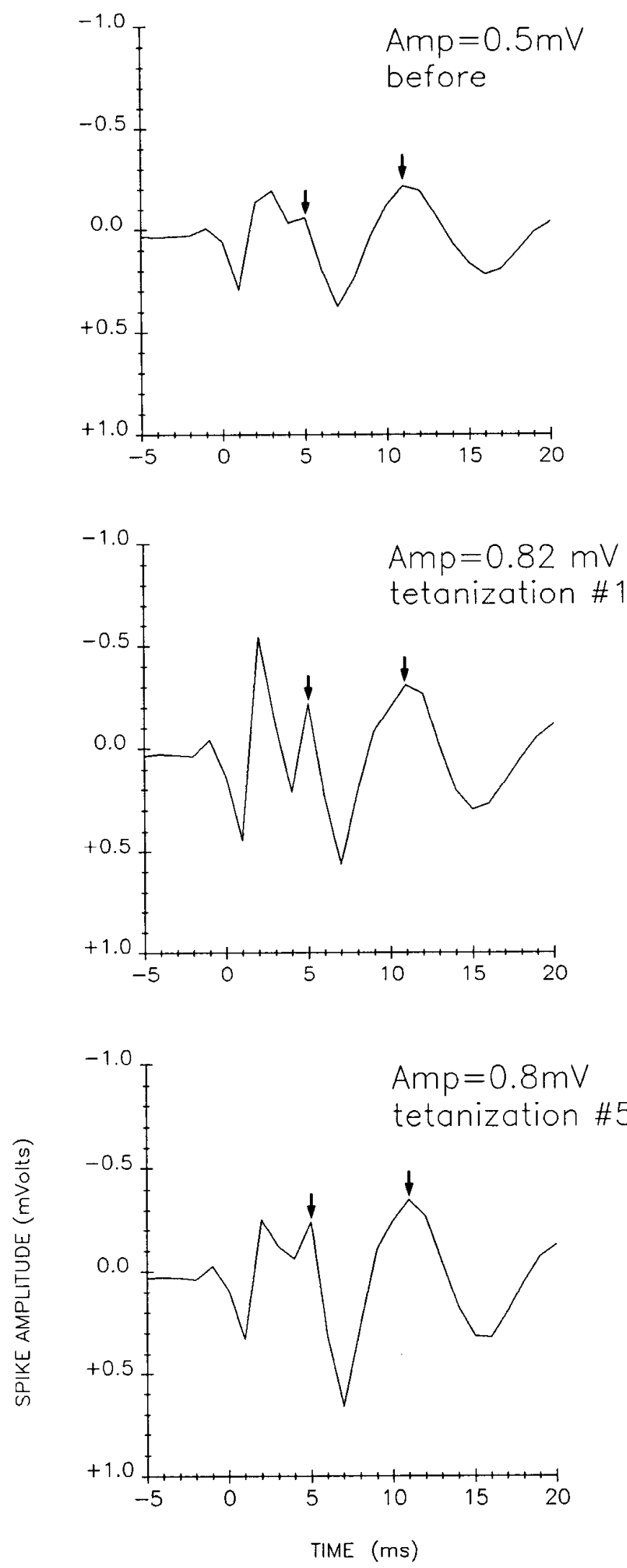
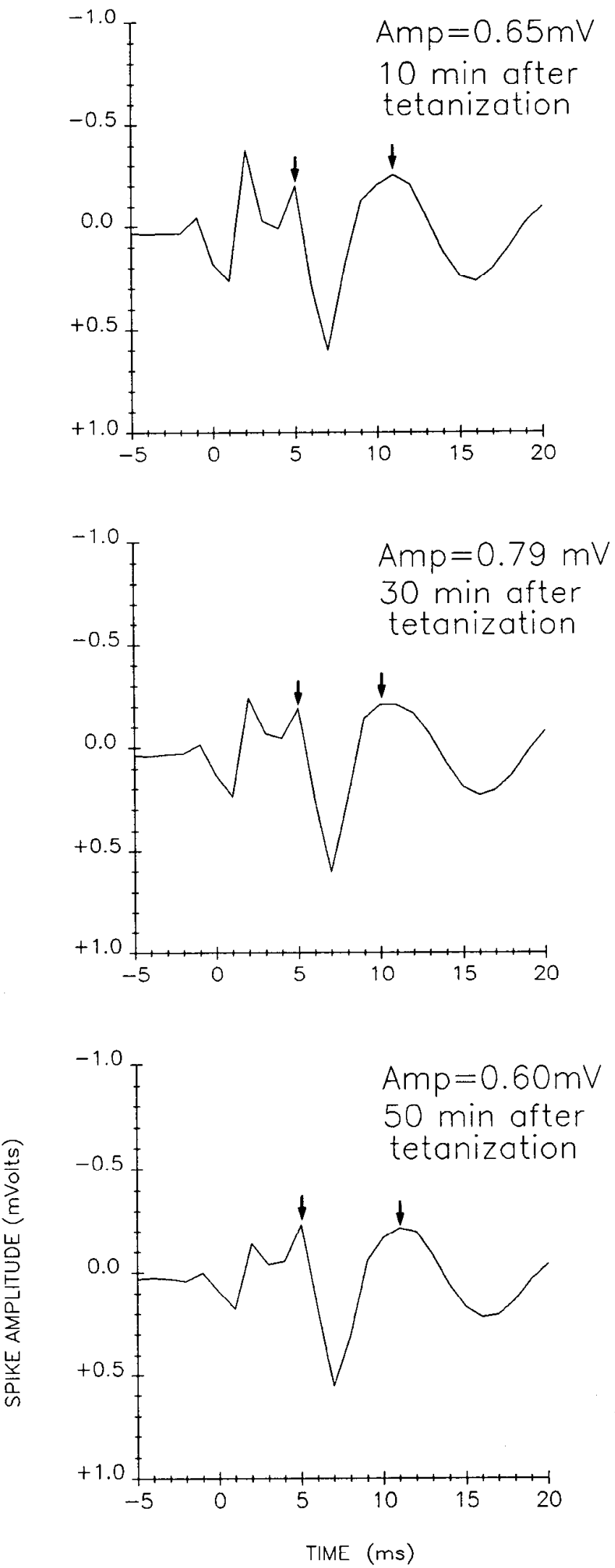

Figure 3. Average evoked potential elicited in the lateral nucleus of the amygdala by the test stimulus before and after tetanization of MGB. Responses to the test stimulus are shown before tetanization, immediately after delivery of the first and fifth tetanizing stimulus, and 10,30 , and 50 min after the fifth tetanizing stimulus. Traces represent the average response to 20 presentations of the test stimulus. Response to each stimulus was digitized (at $2000 \mathrm{~Hz}$ ) on-line and averaged off-line. Amplitude $(A m p)$ of the positive (down-going) potential, shown for each test period, is larger after than before tetanization. The increase in amplitude is maintained for more than 50 min after the final tetanizing stimulus. 

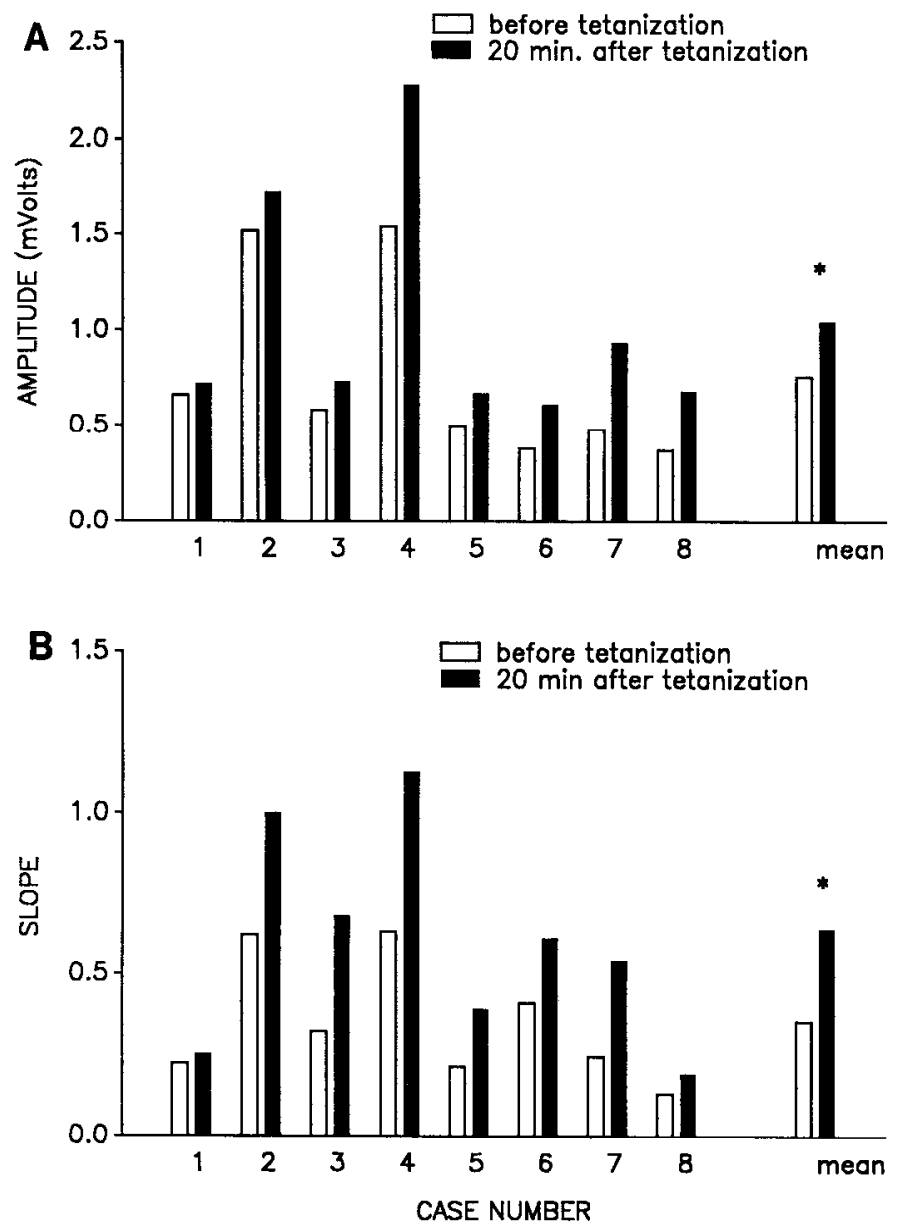

Figure 4. Amplitude $(A)$ and slope $(B)$ of the evoked potential before and $20 \mathrm{~min}$ after the final tetanization in individual rats (case numbers 1-8). The group means before and after are shown at far right. Amplitude and slope were both significantly greater after than before tetanization, as determined by the Student's $t$ test for nonindependent samples $\left(^{*} p\right.$ $<0.01$ ).

concentrated in AL (Monaghan and Cotman, 1985). NMDA receptors are hypothesized to be associated with postsynaptic sites on dendritic spines (Malenka et al., 1989) and most thalamoamygdala fibers terminate on spines in AL (Farb et al., 1989).

LTP is often described as a potential cellular model of memory, particularly of the memory functions of the hippocampus (Andersen et al., 1980; Goddard, 1980; Eccles, 1983, 1987; Lynch and Baudry, 1984). However, the relationship between LTP and memory is controversial (see Swanson et al., 1982; Teyler and DiScenna, 1987; Brown et al., 1988). The difficulty in relating ITP to the memory functions of the hippocampus may, in part, reflect the fact that the stimulation conditions necessary to induce LTP do not readily map onto learning and memory tasks that depend on the hippocampus, such as spatial learning and memory tasks (e.g., O'Keefe and Nadel, 1978; Olton et al., 1979; Barnes, 1988). LTP stimulation conditions, which usually involve "cooperativity" between multiple afferent connections (Bliss and Lomo, 1973; McNaughton et al., 1978; Levy and Steward, 1979; Barrionuevo and Brown, 1983; Lee, 1983); are, in principle, more compatible with the stimulus conditions of classical conditioning, where activity in 2 afferent pathways converges, anatomically and temporally, to produce long-lasting neural and behavioral changes. Although neural

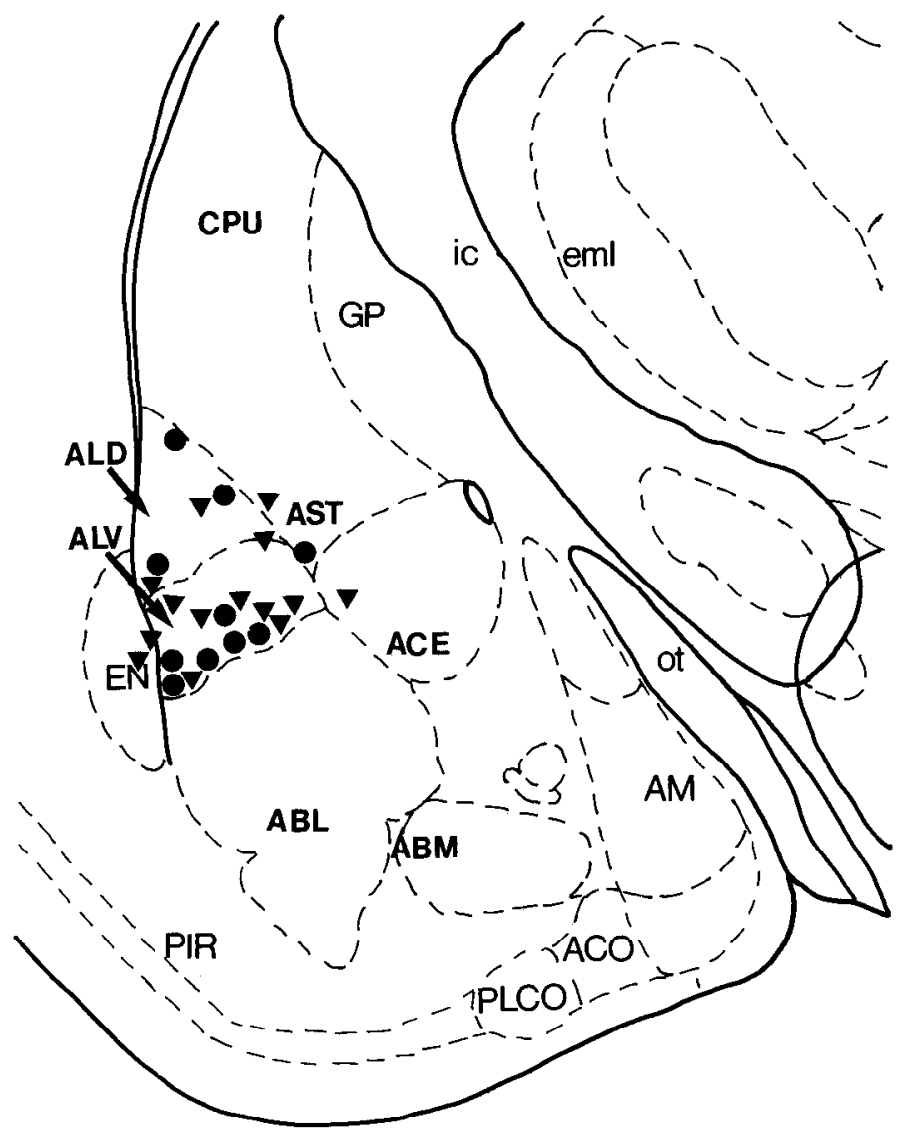

Figure 5. Histological reconstruction of the recording sites. Sites where LTP was induced are shown by circles and sites where LTP was not induced are shown by triangles. All placements were targeted towards the lateral nucleus of the amygdala and most of the effective sites $(9$ of 10) are within this area. LTP was also induced in the amygdalostriatal transition zone, which also receives afferents from the acoustic thalamus. LTP was not induced in the one placement located in the central nucleus of the amygdala or in the placements located in the endopiriform nucleus and external capsule (between endopiriform nucleus and lateral nucleus of amygdala). For placements in the external capsule and endopiriform nucleus, evoked potentials but not unit responses were recorded prior to tetanization. In all other placements, both unit responses and evoked potential were recorded. Abbreviations: $A B L$, basolateral nucleus of the amygdala; $A C E$, central nucleus of the amygdala; $A C O$, anterior cortical nucleus of the amygdala; $A L D$, lateral nucleus of the amygdala, dorsal part; $A L V$, lateral nucleus of the amygdala, ventral part; $A M$, medial nucleus of the amygdala; $A S T$, amygdalostriatal transition area; $C P U$, caudate-putamen; $e m l$, external medullary lamina; $E N$, endopiriform area; $G P$, globus pallidus; $i c$, internal capsule; $P I R$, piriform cortex; $P L C O$, posterolateral cortical nucleus of the amygdala; ot, optic tract.

activity changes in the hippocampus during classical conditioning (Olds et al., 1972; Segal, 1977; Berger and Thompson, 1978; Weisz et al., 1984), the integrity of the hippocampus is not essential for the expression of conditioned behavior in many classical conditioning tasks (see O'Keefe and Nadel, 1978; Moore and Solomon, 1980). In contrast, the thalamoamygdala projection is an essential link in the circuity through which behavioral and autonomic responses are coupled to acoustic stimuli through classical conditioning (LcDoux ct al., 1984, 1986, 1990b; Iwata et al., 1986). The thalamoamygdala projection arises in areas receiving and transmitting both acoustic and spinothalamic information (LeDoux et al., 1987), the input combination necessary for the establishment of conditioned responses to tones associated with footshock. LTP induced in AL by stimulation 
of the thalamus may thus result from the cooperative stimulation of pathways that mediate the relay of conditioned and unconditioned stimulus information to the amygdala during aversive conditioning. Interestingly, LTP has also been demonstrated in the medial areas of the medial geniculate body (Gerren and Weinberger, 1983), where a large proportion of the population of amygdala projection neurons reside (LeDoux et al., 1990a) and where physiological plasticity has been observed in conditioning studies (Olds et al., 1972; Gabriel et al., 1976; Ryugo and Weinberger, 1978). The disadvantage of the thalamoamygdala projection as a model system for studying plasticity (as compared to the hippocampus) is that the amygdala lacks the precise anatomical organization that makes the hippocampus so attractive. While the relation between LTP and memory is likcly to rcmain controversial for some time, tetanization of thalamoamygdala circuitry may offer an interesting alternative to studies of the hippocampus for critically examining the issues.

The fact that LTP has been demonstrated in both the medial $\mathrm{MGB}$ and $\mathrm{AL}$, the origin and termination of the thalamoamygdala fear conditioning pathway, respectively, suggests the possibility of an "LTP cascade" in fear conditioning. Thus, during fear conditioning, synaptic transmission may be facilitated in the acoustic thalamus, and this potentiation may be transmitted and further facilitated in AL. This hypothesis remains to be tested.

In conclusion, our demonstration that tetanization of thalamoamygdala projections induces an enhancement of transmission in AL may go beyond simply being yet another instance of LTP. On the one hand, the finding suggests a possible approach for examining the cellular mechanisms underlying the contribution of thalamoamygdala projections to emotional learning and memory processes. On the other hand, since the thalamoamygdala projection is known to be involved in specific and well-characterized mnemonic functions, the existence of LTP in this circuit may provide a new and viable approach for examining the role of LTP in normal learning and memory processes.

\section{References}

Andersen P, Sundberg SH, Sveen O, Swann JW, Wigström H (1980) Possible mechanisms for long-lasting potentiation of synaptic transmission in hippocampal slices from guinea-pigs. J Physiol (Lond) 302: $463-482$.

Barnes CA (1988) Spatial learning and memory processes: the search for their neurobiological mechanisms in the rat. Trends Neurosci 11: 163-169.

Barrionuevo G. Brown TH (1983) Associative long-term potentiation in hippocampal slices. Proc. Natl Acad Sci USA 80:7347-7351.

Berger TW, Thompson RF (1978) Neuronal plasticity in the limbic system during classical conditioning of the rabbit nictitating membrane response: I. The hippocampus. Brain Res 145:323-346.

Bliss TVP, Lømo T (1973) Long-lasting potentiation of synaptic transmission in the dentate area of the anesthetized rabbit following stimulation of the perforant path. J Physiol (Lond) 232:331-356.

Brown TH, Chapman PF, Kairiss EW, Keenan L (1988) Long-term synaptic potentiation. Science 242:724-728.

Chapman PF, Brown TH (1988) Long-term potentiation in amygdala brain slices. Soc Neurosci Abstr 14:566.

Clugnet MC, LeDoux JE (1989) Long term potentiation (LPT) in the lateral amygdala (AL) in response to stimulation of the medial geniculate body (MGB). Soc Neurosci Abstr 15:891.

Clugnet MC, LeDoux JE, Morrison SF (1990) Unit responses evoked in the amygdala and striatum by electrical stimulation of the medial geniculate body. J Neurosci 10:1055-1061.

Collingridge GL (1985) Long-term potentiation in the hippocampus: mechanisms of initiation and modulation by neurotransmitters. Trends Pharmacol Sci 6:407-411.

Collingridge GL, Kehl SJ, McLennan H (1983) Excitatory amino acids in synaptic transmission in the Schaffer-commissural pathway of the rat hippocampus. J Physiol (Lond) 334:33-46.

Cotman CW, Monaghan DT, Ganong AH (1988) Excitatory amino acid neurotransmission: NMDA receptors and Hebb-type synaptic plasticity. Annu Rev Neurosci 11:61-80.

Dunwiddie T, Madison D, Lynch G (1978) Synaptic transmission is required for initiation of long-term potentiation. Brain Res 150:413417.

Eccles JC (1983) Calcium in long-term potentiation as a model for memory. Neuroscience 4:1071-1081.

Eccles JC (1987) Mechanisms of learning in complex neural systems. In: Handbook of physiology, Section 1: The nervous system. Vol 5, Higher functions of the brain (Plum F, ed), pp 137-167. Bethesda, MD: American Physiological Society.

Farb CF, IeDoux JE, Milner TA (1989) Glutamate is present in medial geniculate body neurons that project to lateral amygdala and in lateral amygdala presynaptic terminals. Soc Neurosci Abstr 15:890.

Gabriel M, Miller JD, Saltwick SE (1976) Multiple unit activity of the rabbit medial geniculate nucleus in conditioning, extinction, and reversal. Physiol Psychol 4:124-134.

Gerren RA, Weinberger NM (1983) Long term potentiation in the magnocellular medial geniculate nucleus of the anesthetized cat. Brain Res 265:138-142.

Goddard G (1980) Component properties of the memory machine: Hebb revisited. In: The nature of thought: essays in honour of D.O. Hebb (Jusczyk PW, Klein RM, eds), pp 231-247. London: Earlbaum.

Harris EW, Ganong AH, Cotman C (1984) Long-term potentiation in the hippocampus involves activation of $\mathrm{N}$-methyl-D-aspartate receptors. Brain Res 323:132-137

Iwata J, LeDoux JE, Meeley MP, Arneric S, Reis DJ (1986) Intrinsic neurons in the amygdaloid field projected to by the medial geniculate body mediate emotional responses conditioned to acoustic stimuli. Brain Res 383:195-214.

LeDoux JE, Sakaguchi A, Reis DJ (1984) Subcortical efferent projections of the medial geniculate nucleus mediate emotional responses conditioned by acoustic stimuli. J Neurosci 4:683-698.

LeDoux JE, Ruggiero DA, Reis DJ (1985) Projections to the subcortical forebrain from anatomically defined regions of the medial geniculate body in the rat. J Comp Neurol 242:182-313.

LeDoux JE, Sakaguchi A, Iwata J, Reis DJ (1986) Interruption of projections from the medial geniculate body to an archi-neostriatal field disrupts the classical conditioning of emotional responses to acoustic stimuli in the rat. Neuroscience 17:615-627.

LeDoux JE, Ruggiero DA, Forrest R, Stornetta R, Reis DJ (1987) Topographic organization of convergent projections to the thalamus from the inferior colliculus and spinal cord in the rat. J Comp Neurol 264:123-146.

LeDoux JE, Farb CF, Ruggiero DA (1990a) Topographic organization of neurons in the acoustic thalamus that project to the amygdala. $J$ Neurosci 10:1043-1054.

LeDoux JE, Cicchetti PO, Xagoraris A, Romanski L (1990b) The lateral amygdaloid nucleus: sensory interface of the amygdala in fear conditioning. J Neurosci 10:1062-1069.

Lee KS (1983) Cooperativity among afferents for the induction of long-term potentiation in the CAl region of the hippocampus. J Neurosci 3:1369-1372.

Levy WB, Steward O (1979) Synapses as associative memory elements in the hippocampal formation. Brain Res 175:233-235.

Lynch G, Baudry M (1984) The biochemistry of memory: a new and specific hypothesis. Science 224:1057-1063.

Malenka RC, Kauer A, Perkel DJ, Nicoll RA (1989) The impact of postsynaptic calcium on synaptic transmission-its role in long-term potentiation. Trends Neurosci 12:444-450.

McNaughton BL, Douglas RM, Goddard GV (1978) Synaptic enhancement in fascia dentata: cooperativity among coactive afferents. Brain Res 157:277-293.

Monaghan DT, Cotman CW (1985) Distribution of N-methyl-D-aspartate-sensitive L- $\left({ }^{3} \mathrm{H}\right)$ glutamate-binding sites in rat brain. J Neurosci 5:2909-2919.

Moore JW, Solomon PR, eds (1980) The role of the hippocampus in learning and memory: a memorial workshop to AH Black. Physiol Psychol 8. 
Morris RGM, Andersen P, Lynch GS, Baudry M (1986) Selective impairment of learning and blockade of long-term potentiation by an $\mathrm{N}$-methyl-D-aspartate receptor antagonist, AP5. Nature 319:774-776.

Nowak L, Bregestovski P, Ascher P, Herbet A, Prochiantz A (1984) Magnesium gates glutamate-activated channels in mouse central neurones. Nature 307:462-464.

O'Keefe J, Nadel L (1978) The hippocampus as a cognitive map. Oxford, UK: Clarendon.

Olds J, Disterhoft JF, Segal M, Hornblith CL, Hirsch R (1972) Learning centers of rat brain mapped by measuring latencies of conditioned unit responses. J Neurophysiol 35:202-219.

Olton D, Becker JT, Handleman GE (1979) Hippocampus, space and memory. Behav Brain Sci 2:313-365.

Ryugo DK, Weinberger NM (1978) Differential plasticity of morphologically distinct neuron populations in the medial geniculate body of the cat during classical conditioning. Behav Biol 22:275-301.
Segal M (1977) Excitability changes in rat hippocampus during conditioning. Exp Neurol 55:67-73.

Swanson LW, Teyler TJ, Thompson RF, eds (1982) Hippocampal LTP: mechanisms and functional implications. Neurosci Res Prog 20:613-769.

Teyler TJ, DiScenna P (1987) Long-term potentiation. Annu Rev Neurosci 10:131-161.

Weisz DJ, Clark GA, Thompson RF (1984) Increased responsivity of dentate granule cells during nicitating membrane response conditioning in rabbit. Brain Res 112:145-154.

Wigstrøm H, Gustafsson B (1985) On long-lasting potentiation in the hippocampus: a proposed mechanism for its dependence on coincident pre- and postsynaptic activity. Acta Physiol Scand 123:519-522. 